\title{
Case Report and Review of the Literature
}

\section{Airway Challenges in Sanjad-Sakati Syndrome (SSS): A Case Report and Review of Literature}

\author{
Mohamed A. Khalil ${ }^{12 *}$, Alaa M. Khidr ${ }^{2}$, Talal M. Alghamdi' and Najeebah A. Al Elk ${ }^{3}$ \\ ${ }^{1}$ Anesthesia Department, Cairo University, Giza, Egypt \\ ${ }^{2}$ Anesthesia Department, King Fahd Hospital of Imam Abdulrahman Bin Faisal University, Al Khobar, Saudi Arabia \\ ${ }^{3}$ Resident, Ministry of Health, Saudi Arabia
}

\begin{tabular}{l} 
A R T I C L E I N F O \\
\hline Article history: \\
Received: 15 June, 2021 \\
Accepted: 28 June, 2021 \\
Published: 13 July, 2021 \\
\hline Keywords: \\
Sanjad-Sakati Syndrome \\
Airway Challenges \\
Congenital Hypoparathyroidism
\end{tabular}

\begin{abstract}
A B S T R ACT
Sanjad-Sakati Syndrome (SSS) is a rare syndrome, discovered in Saudi Arabia in 1988. This syndrome is characterized by congenital hypoparathyroidism, severe growth retardation, dysmorphic features, mild to severe mental retardation as well as recurrent chest infections. We presented an eight-year-girl with SSS, with severe growth retardation, mental retardation, resolution of recent chest infection together with a history of bronchial asthma, dysmorphic features, limited mouth opening, micrognathia as well as high susceptibility to difficult intubation. The objective of this case report is to present the successful anaesthetic management of a rare genetic endocrinal syndrome.
\end{abstract}

(C) 2021 Mohamed A. Khalil. Hosting by Science Repository.

\section{Introduction}

Sanjad-Sakati Syndrome (SSS) was first reported in Saudi Arabia in 1988, also known as hypoparathyroidism-retardation-dysmorphism syndrome [1]. This syndrome is found mainly in Arabian children; however, the disease was reported also in some non-Arabian children [2]. The main disorder in affected children is the hypoparathyroidism. Consequently, the main presentations would be hypocalcemia, hyperphosphatemia, mild to severe mental and growth retardation, seizures, dysmorphic features (micrognathia, abnormal dentition, and dentofacial anomalies), and recurrent chest infections [3]. Anaesthetic management of these patients poses great challenges owing to the susceptibility to difficult intubation, recurrent chest infections as well as great sensitivity to muscle relaxants [4].

\section{Case Description}

An eight-year-old Saudi girl, presented to our hospital for full oral rehabilitation and dental extractions. This girl complains from SSS since birth with congenital hypoparathyroidism, hypocalcemia, hyperphosphatemia, mental retardation, delayed developmental milestones (weight $8.6 \mathrm{Kg}$, height $77 \mathrm{~cm}$ ) (Figure 1), bronchial asthma and recurrent chest infections. The patient has dysmorphic features, micrognathia, and limited mouth opening and refuses to examine her airway (Figure 2). After optimization of the general condition, correction of electrolyte disturbances and treatment of the last attack of chest infection, the patient was scheduled for full mouth rehabilitation \& teeth extractions surgery.

The patient came with a G24 venous catheter; induction of general anaesthesia was performed by midazolam $1 \mathrm{mg}$ I.V., propofol $20 \mathrm{mg} \mathrm{I.V.}$ and fentanyl $8 \mu \mathrm{g}$ I.V. There was a high suspicion for a difficult airway, so trolley of difficult intubation was prepared prior to induction of general anaesthesia. Examination of the airway revealed a Mallampati grade 3, so external neck compression was used in order to facilitate intubation. Trial for direct laryngoscopy and nasotracheal intubation using the Macintosh blade size 2 was failed. Consequently, McGrath Video-laryngoscope blade size 2 was used successfully for intubation. Magill forceps was used to facilitate the nasotracheal intubation together

${ }^{*}$ Correspondence to: Mohamed A. Khalil, M.D., Anesthesia Department, Cairo University, Giza, Egypt

King Fahd Hospital of Imam Abdulrahman Bin Faisal University, King Faisal Road, Al Yarmook, Al Khobar, 34422, Saudi Arabia; Tel: +966545965581; E-mail: mohamedkhalil404@hotmail.com 
with insertion of an oral throat pack. Airway was secured by insertion of nasotracheal re-inforced $4.5 \mathrm{~mm}$ internal diameter cuffed tube.

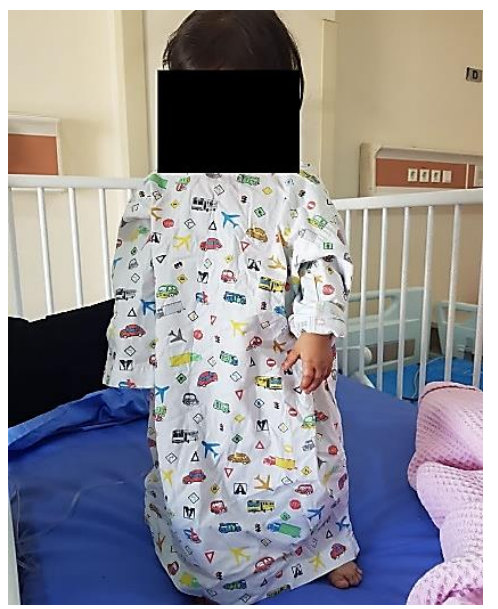

Figure 1: The delayed developmental milestones of the patient with Sanjad-Sakati Syndrome (SSS).

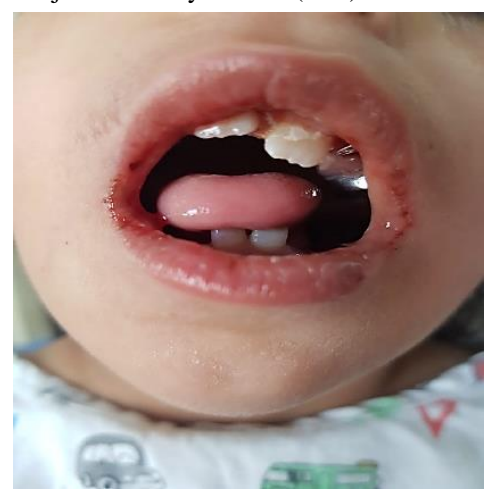

Figure 2: The micrognathia \& the limited mouth opening of the patient with Sanjad-Sakati Syndrome (SSS).

Anaesthesia was maintained by Sevoflurane in Oxygen 50\% together with fentanyl boluses upon request. Near the end of surgery, the patient received paracetamol $120 \mathrm{mg}$ I.V. Surgery lasts about 3 hours, patient was smoothly extubated and shifted fully awake to the PICU (Pediatric Intensive Care Unit) for postoperative follow-up and observation. Being sensitive to muscle relaxants, none was used neither for intubation nor for maintenance of general anaesthesia.

\section{Discussion}

The main disorder in SSS is hypoparathyroidism resulting in hypocalcemia, tetany and seizures [1, 2]. Affected patients have characteristic abnormal facial features as the long narrow face, deep eyes, beaked nose, large floppy ears, and micrognathia [4]. They usually present in the early postnatal period with manifestations of hypocalcemia owing to the hypoparathyroidism [3]. Due to the facial abnormalities, they usually come to the operating room for repeated fractures as well as oral rehabilitation and dental extractions [4]. Anaesthetic management of these patients pose an anaesthetic challenge due to susceptibility for difficult intubation, growth retardation, micrognathia, limited mouth opening, repeated chest infections as well as inappropriate response to muscle relaxants [5]. Preoperative assessment, amelioration of the general condition and preoperative treatment of any electrolyte abnormality or chest infection are mandatory for a successful anaesthetic management. In our case, the patient's airway was expected to be difficult owing to the micrognathia as well as the very limited mouth opening. Therefore, trolley of difficult intubation was prepared prior to induction of general anaesthesia. McGrath Video-laryngoscope played an important role in securing the airway after failure of use of the Macintosh in insertion of the nasotracheal tube [6]. Availability of different tube sizes prior to induction of anaesthesia is mandatory before facing surprises. In our case, we inserted a $4.5 \mathrm{~mm}$ internal diameter cuffed tube in an eight-year-old girl, the presence of this unexpected size in the operating room saved a great time before intubation. Additionally, the present hypocalcemia and hyperphosphatemia were corrected preoperatively in order to reduce the incidence of intraoperative arrhythmias and laryngospasm. A PICU bed was reserved for our patient for postoperative observation and follow up especially that there is a high incidence for central hypoventilation. Owing to the high susceptibility to central respiratory depression, avoidance of opioid agents is preferred together with the use of non-opioids as paracetamol in order to control the post-operative pain [7].

\section{Conclusion}

SSS is a rare syndrome which was discovered originally in Saudi Arabia. Good preoperative optimization of the general condition and correction of associated co-morbidities as metabolic, electrolyte disturbances as well as treatment of recurrent chest infections, are mandatory in-order to reach a smooth intraoperative course. One of the most important challenges in the anaesthetic management of these cases is the higher susceptibility for difficult intubation owing to the micrognathia and small mouth opening. To take home message is careful and optimum preparation of difficult intubation trolley with different tube sizes as well as the availability of modern equipment for tracheal intubation, as the Video-laryngoscope, are of high importance in the anaesthetic management of these cases.

\section{Author Contributions}

Mohamed A. Khalil: This author was the consultant Anaesthetist who took over the intra-operative anaesthetic management of the case as well as writing the manuscript; Alaa M. Khidr: This author helped in gathering the literature information regarding this extremely rare syndrome; Talal M. Alghamdi: This author helped in revision of the manuscript; Najeebah A. Al Elk: This author helped in the preoperative preparation as well as follow-up of the optimization of the case.

\section{Consent}

A written informed consent was signed by the mother for agreement of the publication of the case as well as taking photos of the girl.

\section{Disclosure}

This manuscript adheres to the applicable EQUATOR (Enhancing the Quality and Transparency of Health Research) guideline.

\section{Funding}

None. 


\section{Conflicts of Interest}

None.

\section{Abbreviation}

SSS: Sanjad-Sakati Syndrome

EQUATOR: Enhancing the Quality and Transparency of Health Research

PICU: Pediatric Intensive Care Unit

\section{REFERENCES}

1. Sanjad S, Sakati N, Abu Osba Y (1988) Congenital hypoparathyroidism with dysmorphic features: a new syndrome. Pediatr Res 23.

2. Sen C, Pal S, Sengupta P, Pal A, Ganguly J et al. (2016) Sanjad-Sakati syndrome: Beyond the Middle-East. Indian J Cereb Palsy 2: 54-57.
3. Sanjad SA, Sakati NA, Abu Osba YK, Kaddoura R, Milner RD (1991) A new syndrome of congenital hypoparathyroidism, severe growth failure, and dysmorphic features. Arch Dis Child 66: 193-196. [Crossref]

4. Kalam MA, Hafeez W (1992) Congenital hypoparathyroidism, seizure, extreme growth failure with developmental delay and dysmorphic features--another case of this new syndrome. Clin Genet 42: 110-113. [Crossref]

5. Platis CM, Wasersprung D, Kachko L, Tsunzer I, Katz J (2006) Anesthesia management for the child with Sanjad-Sakati syndrome. Paediatr Anaesth 16: 1189-1192. [Crossref]

6. Kwak HJ, Lee SY, Lee SY, Cho SH, Kim HS et al. (2016) McGrath Video Laryngoscopy Facilitates Routine Nasotracheal Intubation in Patients Undergoing Oral and Maxillofacial Surgery: A Comparison With Macintosh Laryngoscopy. J Oral Maxillofac Surg 74: 256-261. [Crossref]

7. Marcus CL, Brooks LJ, Draper KA, Gozal D, Halbower AC et al (2012) Diagnosis and management of childhood obstructive sleep apnea syndrome. Pediatrics 130: e714-e755. [Crossref] 